\title{
Rethinking water resources management from water -energy nexus perspective - a research and comparison of Jing-Jin-Ji Region of China and California of the United States
}

\author{
Shan Jiang ${ }^{1,2, *}$, Yongnan Zhu ${ }^{1,2}$, Lizhen Wang ${ }^{1,2}$ Qingming Wang ${ }^{1,2}$, Guohua $\mathrm{He}^{1,2}$, \\ ${ }^{1}$ China Institute of Water Resources and Hydropower Research, State Key Laboratory of Simulation and Regulation of Water Cycle in \\ River Basin, 100038, Beijing, China; \\ ${ }^{2}$ China Institute of Water Resources and Hydropower Research, Department of Water Resources, 100038, Beijing, China
}

\begin{abstract}
The relationship between water and energy is extremely close and complex, especially in water use system. However, the energy consumption of water systems has been ignored in water resources management due to the lack of deep understanding of the water-energy nexus. Based on analysis of waterrelated energy in water use, this paper selected Jing-Jin-Ji region of China and California of the United States to conduct a research study and found that the energy consumption of water use systems accounted for about $16 \%$ and $20 \%$ of the total electricity consumption of Jing-Jin-Ji region and California, respectively, water use has shifted more energy-intensive. This paper systematically quantified the urban water-energy relationship, analyzed the water supply structure and the energy efficiency and energy consumption in different water system sectors, and found that California's total water use is 3.3 times that of Jing-Jin-Ji region, but the energy consumption of California's water systems is only 2.3 times that of Jing-Jin-Ji region. This study suggests that water conservation is a cost-effective way to save energy, and it is necessary to quantitatively analyze the water-energy nexus for a more comprehensive and deep understanding of water resources management.
\end{abstract}

\section{Introduction}

With rapid urbanization and industrialization, water use in urban consumed a considerable amount of energy for water supply, distribution and wastewater treatment [1]. Energy consumption with water cycle is one of the key concepts of water-energy nexus. Approximately 7\% of the commercial energy generated is used for water cycle around the world [2], and $13 \%$ of electricity and $18 \%$ of natural gas is estimated to be water-related in Australian cities [3]. California Energy Commission demonstrated that $19 \%$ of the electricity and $32 \%$ natural gas was water-related in California [4]. Water-energy nexus studies show that energy embedded in the water cycle accounts for a small proportion in total energy use with large absolute values which is significant for energy and water conservation from demand-side management.

In the cities, water and energy form interconnected systems that changes in one system impact the other system, especially in water service cycle. The Jing-Jin-Ji region, also known as Beijing-Tianjin-Hebei Metropolitan Region, including Beijing Municipality, Tianjin Municipality and Hebei Province, is one of the three major economic regions in China. Jing-Jin-Ji region has been facing severe shortage of water resources and has a tremendous conflict of interest in water supply and demand [5]. California is a state in the
Pacific Region of the United States (U.S.), which is the most populous U.S. state and the largest sub-national economy in the world. California has important linkages between water and energy supply and demand [6], especially in southern part of the state, which is highpopulated and typically exhibits an arid and desert climate with little natural precipitation. With the fast development of economy, both Jing-Jin-Ji Region and California are facing the great challenges of increasing water and energy demand, water shortages, carbon caps, and environment and resource protection. It is therefore important to analyze water and energy nexus between Jing-Jin-Ji region and California to improve and sustain water resources management in large metropolitan areas.

\section{Method}

The processes of water intake, supply, distribution, consumption, drainage, and reuse are often involved with energy.

\subsection{Surface water conveyance}

Surface water projects are primarily divided into water storage, water diversion, water extraction, and crossbasin water transfer. Based on Darcy's formula, the

*Corresponding author: Shan Jiang (jiangs@iwhr.com) 
friction head loss of reinforced concrete pipe can be calculated using the following formulas:

$$
\begin{gathered}
h_{f}=i \times L \\
\mathrm{i}=10.294 \times n^{2} \times Q^{2} \div d^{5.333}
\end{gathered}
$$

Formula for calculating the energy consumption of surface water is as follows:

$$
\mathrm{w}=\frac{\mathrm{mgh}}{3.6 \times 10^{6}}
$$

where $\mathrm{w}$ is the energy consumption for surface water intake $(\mathrm{kWh}) ; \mathrm{m}$ is the mass of water conveyed $(\mathrm{kg})$; $\mathrm{g}$ is the gravitational acceleration $(\mathrm{N} / \mathrm{kg}) ; \mathrm{h}$ is the height of conveyance; $h_{\mathrm{f}}$ is the frictional head loss $(\mathrm{m}) ; \mathrm{i}$ is the head loss per unit length $(\mathrm{m} / \mathrm{m})$; $\mathrm{L}$ is the length of the calculated pipe segment $(\mathrm{m}) ; \mathrm{n}$ is the roughness coefficient; Q is the flow of the pipe segment $\left(\mathrm{m}^{3} / \mathrm{s}\right)$; and $\mathrm{d}$ is the inner diameter of the pipe (m).

\subsection{Ground water pumping}

The energy consumption of surface water exploitation mainly comes from pumping stations, and it depends on the depth of the surface water, the amount of pumping, along with the type and efficiency of the pump.

$$
\mathrm{W}=\frac{m g \times h}{3.6 \times 10^{6} \times \varepsilon \times(1-\eta)}
$$

where $\mathrm{h}$ is the depth of surface water; $\varepsilon$ is the efficiency of the pumping station; and $\eta$ is the wear-and-tear along the way.

\subsection{Distribution and treatment}

Different water users have different requirements for water quality, which requires energy consumption to process and distribute different water sources. Treated water is transferred to water distribution network to supply water to end users using water delivery pipelines.

\subsection{Water end-uses}

Water end-users are usually classified into residential, commercial/industrial, and agricultural water users, with different energy requirements for different uses. Energy consumption for water heating can be estimated using the following formula:

$$
\begin{aligned}
& E_{h}=\frac{V \times \rho \times C \times\left(T_{t}-T_{i}\right)}{\mu}+E \\
& e_{h}=\frac{E_{h}}{Q \times 3.6 \times 10^{3}}
\end{aligned}
$$

where $E_{h}$ is the energy consumption of water heating $(\mathrm{KJ}) ; \mathrm{e}_{\mathrm{h}}$ is the energy intensity of water heating $\left(\mathrm{kWh} / \mathrm{m}^{3}\right)$; Q is the water volume for heating $\left(\mathrm{m}^{3}\right) ; \mu$ is the energy consumption coefficient; $\mathrm{E}$ is the standby heat damage $(\mathrm{KJ}) ; \mathrm{T}_{\mathrm{t}}$ is the thermostatic temperature of the heater $\left({ }^{\circ} \mathrm{C}\right)$; $\mathrm{T}_{\mathrm{i}}$ is the air temperature $\left({ }^{\circ} \mathrm{C}\right) ; \mathrm{V}$ is the water storage volume $(\mathrm{L}) ; \rho$ is the water density $(\mathrm{kg} / \mathrm{L})$; and $\mathrm{C}$ is the specific heat capacity of water $\mathrm{kJ} /\left(\mathrm{kg} \cdot{ }^{\circ} \mathrm{C}\right)$.

The mechanical energy consumption formula is as follows:

$$
E_{m}=p \times m \times 3600
$$

$$
e_{m}=\frac{E_{m}}{Q \times 3.6 \times 10^{3}}
$$

where $E_{m}$ is the total mechanical energy consumption $(\mathrm{kWh}) ; e_{m}$ is the energy consumption intensity of water utilization $\left(\mathrm{kWh} / \mathrm{m}^{3}\right) ; Q$ is the total water consumption quantity during machine operation $\left(\mathrm{m}^{3}\right) ; p$ is the rated power $(\mathrm{kWh} / \mathrm{kg})$; and $m$ is the rated capacity $(\mathrm{kg})$.

\subsection{Waste water treatment}

Sewage treatment can be classified into two categories. First, wastewater is collected by the drainage network to sewage treatment plant, treated by sinking to remove pollutants that are liable to settle, bioprocessed, and then discharged into the environment. Second, after proper treatment, the wastewater reaches a certain water quality index, and then is used for surface water recharge, industrial, urban non-drinking water, landscaping, and environmental purposes.

\section{Results}

\subsection{Comparison between the water supply structure of Jing-Jin-Ji and California}

Total water supply in Jing-Jin-Ji Region was $24.9 \mathrm{~km}^{3}$ in 2016. As Fig. 1 shows, groundwater was the main water source for the area, accounting for $59 \%$ of the total water supply. Surface water accounted for $33 \%$ of the total water supply, with the Central Line Project of South-toNorth Water Diversion transferring over $3 \mathrm{~km}^{3}$ of water to Jing-Jin-Ji region annually. The unconventional water usage accounted for about $8 \%$ of the total water supply. In 2016, water supply in California reached $74.5 \mathrm{~km}^{3}$, with surface water accounting for approximately $54 \%$ of total water supply and famous California State Water Project transferring $5.2 \mathrm{~km}^{3}$ of water annually. About $70 \%$ of the water was used for the urban areas and industries in southern California and the San Francisco Bay Area, and 30\% was used for agriculture in the Central Valley. Surface water is also an important part of California ' s water supply, accounting for approximately $54 \%$ of the total water supply. Recycled water accounted for about $20 \%$ of the total water supply.

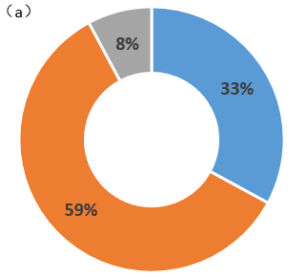

Fig. 1 Water supply structure: (a) Jing-Jin-Ji Region (b)

\subsection{Comparison between the water use structure of Jing-Jin-Ji and California}

Agriculture remains the largest water user in Jing-Jin-Ji and California, accounting for about $61 \%$ of the total water usage in Jing-Jin-Ji and about $45 \%$ in California 
(Fig. 2). Due to different statistical dimensions, California' s ecological water usage refers to the water needed to maintain habitats in streams, to support wetlands in wildlife reserves, and to maintain the water quality for agricultural and urban use, which accounts for $44 \%$ of the total water consumption. While the ecological water usage of China refers to the minimum amount of water required for ecological environment restoration and construction or the maintenance of the current ecological environment quality, and hence the ecological water usage in Jing-Jin-Ji accounts for only $9 \%$ of the total water consumption. The residential water consumption in both Jing-Jin-Ji and California exceeds industrial water consumption. The residential and industrial water consumption account for $20 \%$ and $12 \%$ in Jing-Jin-Ji, respectively, and they account for $10 \%$ and $1 \%$ in California, respectively.
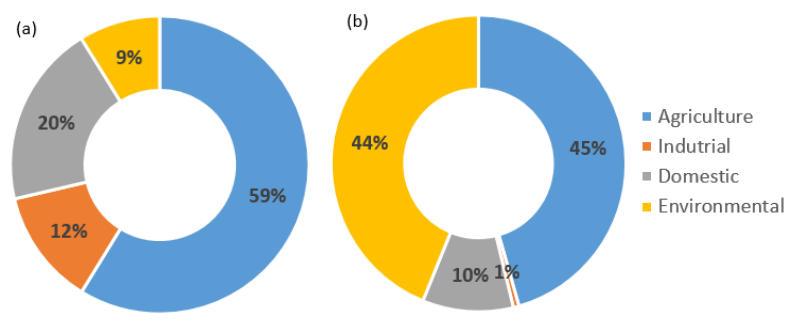

Fig. 2 Water usage structure: (a) Jing-Jin-Ji Region; (b) California.

\subsection{Comparison of unit energy consumption in different water system sectors}

Unit energy consumption of the surface water use in California is more than that in Jing-Jin-Ji region (table 1). This is because the surface water in California is mainly drawn through the Colorado River Aqueduct, the Central Valley Project, and the California State Water Project which consumes $2.62 \mathrm{kWh}$ of electricity per $\mathrm{m}^{3}$ of water transported. The trans-basin water transfer in Jing-Jin-Ji region primarily comes from the Central Line Project of South-to-North Water Diversion, which mainly uses gravity to divert water and require little energy consumption, and only the diversion of water from Hebei province to Beijing requires pumping stations. In the process of groundwater extraction, as the groundwater level in Jing-Jin-Ji region is lower than that in California, the energy consumption per $\mathrm{m}^{3}$ of groundwater extraction is relatively large. The energy consumption per $\mathrm{m}^{3}$ of groundwater extraction for living is $0.33 \mathrm{kWh}$ and that for agricultural irrigation is $0.52 \mathrm{kWh}$.

During conventional water treatment, the power consumption of Jing-Jin-Ji and California is roughly equivalent. However, California has relatively mature technologies for reclaimed water and seawater desalination. It only needs $4.23 \mathrm{kWh}$ of electricity per unit of seawater, which is lower than that in Jing-Jin-Ji region. In the process of water transfer, owing to the differences in water plant layout, building height, and water pressure requirements, the two areas are very different. As the buildings in Jing-Jin-Ji region are denser and the building height is usually high, the unit energy consumption is high. In the process of sewage treatment, because California's sewage treatment standard is slightly higher than Jing-Jin-Ji region, its energy consumption is about $0.5 \mathrm{kWh} / \mathrm{m}^{3}$, compared with $0.31 \mathrm{kWh} / \mathrm{m}^{3}$ in Jing-Jin-Ji region.

Owing to water resource constraints, in the process of water usage the specialized sectors of the economy in California tend to be productive and water efficient. Additionally, during the severe 2012 drought in California, great efforts were made to develop watersaving technologies to improve the reuse rate of industrial water. Repetitive use rate of industrial water are a leader in the world, and the energy consumption per $\mathrm{m}^{3}$ of industrial water in California is $124.7 \mathrm{kWh}$, and in Jing-Jin-Ji region, it is about half that of California. The energy consumption in the process of residential and public water usage mainly comes from heating and mechanical works. The energy consumption per unit of residential and public water in California reaches $21.39 \mathrm{kWh}$; while in Jing-Jin-Ji, it is about $18.26 \mathrm{kWh}$.

Table 1 Comparison of unit energy consumption in different water usage sectors (Unit: $\mathrm{kWh} / \mathrm{m}^{3}$ )

\begin{tabular}{|c|c|c|c|}
\hline \multirow{2}{*}{ Process } & $\begin{array}{c}\text { Jing-Jin-Ji } \\
\text { region }\end{array}$ & California \\
\hline \multicolumn{2}{|c|}{ Surface water } & 0.12 & 0.18 \\
\hline \multicolumn{2}{|c|}{ Water extraction } & 0.08 & 0.04 \\
\hline \multicolumn{2}{|c|}{$\begin{array}{c}\text { Cross-basin water } \\
\text { transfer }\end{array}$} & 1.46 & 2.62 \\
\hline \multicolumn{2}{|c|}{ Groundwater } & 0.33 & 0.2 \\
\hline \multicolumn{2}{|c|}{ Reclaimed water } & 0.82 & 0.66 \\
\hline \multirow{2}{*}{$\begin{array}{c}\text { Water } \\
\text { treatmen } \\
\mathrm{t}\end{array}$} & $\begin{array}{c}\text { Convention } \\
\text { al water }\end{array}$ & 0.36 & 0.37 \\
\cline { 2 - 4 } & $\begin{array}{c}\text { Desalinatio } \\
\mathrm{n}\end{array}$ & 5.9 & 4.23 \\
\hline \multicolumn{2}{|c|}{ Water conveyance } & 0.47 & 0.31 \\
\hline \multirow{2}{*}{$\begin{array}{c}\text { Water } \\
\text { end user }\end{array}$} & Agricultural & 0.52 & 0.4 \\
\cline { 2 - 4 } & $\begin{array}{c}\text { Residential } \\
\text { and public }\end{array}$ & 61.4 & 124.7 \\
\hline \multicolumn{2}{|c|}{ Sewage treatment } & 0.31 & 0.50 \\
\hline \multicolumn{2}{|c|}{} & 18.26 & 21.39 \\
\hline
\end{tabular}

\subsection{Energy consumption in different water system sectors}

The energy consumption of the water systems in California has reached $176 \mathrm{TWh}$, accounting for approximately $20 \%$ of its total electricity consumption. The energy consumption of the water systems in JingJin-Ji region is $75.8 \mathrm{TWh}$, accounting for approximately $16 \%$ of its total electricity consumption. California's total water use is 3.3 times that of Jing-Jin-Ji region, but the energy consumption of its water system is only 2.3 times that of Jing-Jin-Ji region. In the entire water use chain which is shown in Fig. 3, About 89.7 TWh of electricity in California was consumed for residential and commercial water uses, accounting for about $51 \%$ of the energy consumption in water use. While in Jing-JinJi region, about $50 \%$ of the energy consumption is for 
the residential and commercial water uses. Industrial water use was the second largest energy consumer, accounting for about $35 \%$ of energy consumed for water systems in California, and about $28 \%$ in Jing-Jin-Ji region. Agricultural water use is mainly for irrigation, agriculture is concentrated in California Central Valley, as well as Hebei province which relies on groundwater for irrigation is the main breadbasket in Jing-Jin-Ji region, California consumed 3.5 TWh for agricultural irrigation, and Jing-Jin-Ji region 6.7 TWh.

For surface water conveyance, California was a large energy user, consuming about $7038 \mathrm{GWh}$ of electricity, while Jing-Jin-Ji region only consumed $335 \mathrm{GWh}$ of electricity for groundwater extraction, storage, and crossbasin water transfer. Extracting groundwater was also energy intensive in both California and Jing-Jin-Ji region. About 5.3 TWh of electricity was used to extract groundwater in California, accounting for about 3\% of the total energy consumption in the water system sectors. The energy consumption of groundwater extraction in Jing-Jin-Ji region was $1.4 \mathrm{TWh}$, accounting for $2 \%$ of its total energy consumption of water use. The energy consumption of conventional water treatment, unconventional water treatment (including desalinated and reclaimed water), and water conveyance and distribution in California accounted for about $3 \%$ of the total energy consumption. In Jing-Jin-Ji region, however, owing to the large energy consumption of water conveyance and distribution, the energy consumption of conventional water treatment, unconventional water treatment, and water conveyance and distribution accounted for about $9 \%$ of the total energy consumption. For sewage treatment, both California and Jing-Jin-Ji region accounted for about $2 \%$ of the energy consumption in water systems.

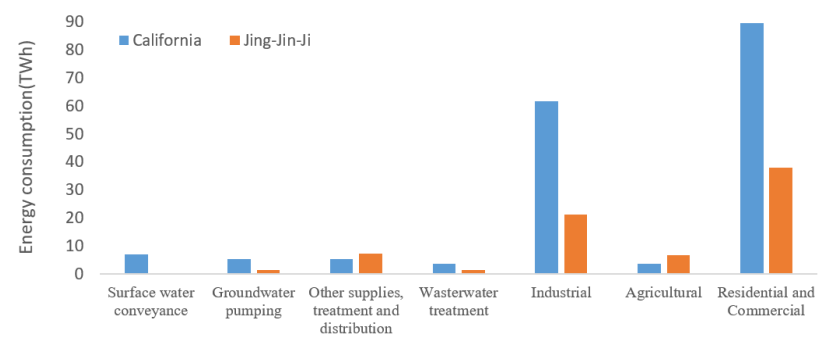

Fig. 3 Energy consumption in water sector in California and Jing-Jin-Ji region

\section{Discussion and Conclusion}

This paper selected Jing-Jin-Ji region of China and California of the United States for research and found that the energy consumption of water use accounted for $16 \%$ and $20 \%$ of the total electricity consumption, respectively. Cities with severe water shortages, with the increase of cross-basin water transfer and desalination, if the allocation of water resources is not reasonable, the cost of urban water system will surge, and the conflict between urban water and energy will intensify.

Compared to exploring new water resources, saving water in the end use is not only alleviating water scarcity but also reducing energy consumption. Adopt tough water management measures in Jing-Jin-Ji Region and California could achieve win-win situation for conserving energy and water. This study shows that for a more comprehensive and deep understanding of the relationship between water and energy, it is necessary to quantitatively analyze the relationship between water and energy from different regions and cities. Although water conservation is a cost-effective way to save energy, it is still necessary to optimize the high energy consumption sectors of urban water system, based on the relationship between water and energy while considering the trade-offs between environmental protection and water supply security.

\section{Acknowledgment}

This research was supported by the International Science \& Technology Cooperation Program of China (Grant No. 2018YFE0196000) and National Nature Science Fund of China (NSFC) (No. 51809282).

\section{References}

1. Valek, A.M., Sušnik, J., Grafakos, S., Quantification of the urban water-energy nexus in México City, México, with an assessment of water-system related carbon emissions. SCI TOTAL ENVIRON, 258-268 (2017).

2. Bazilian, M., Rogner, H., Howells, M., Hermann, S., et al,. Considering the energy, water and food nexus: Towards an integrated modelling approach. 39, 7896-7906 (2011).

3. Kenway, S., Priestley, Lant, P.A., (2010). Quantifying the link between water and energy in cities, Water \& Energy.

4. Kenway, S., McMahon, J., Elmer, V., Conrad, S., Rosenblum, J. Managing water-related energy in future cities - a research and policy roadmap. J WATER CLIM CHANGE 4, 161-175 (2013).

5. Han, J., Wang, J., Zhao, Y., Wang, Q., Zhang, B., Li, H., Zhai, J.,. Spatio-temporal variation of potential evapotranspiration and climatic drivers in the Jing-Jin-Ji region, North China. AGR FOREST METEOROL 256-257, 75-83 (2018).

6. Dale, L.L., Karali, N., Millstein, D., Carnall, M., et al,. An integrated assessment of water-energy and climate change in sacramento, california: how strong is the nexus? CLIMATIC CHANGE 132, 223-235, (2015). 